\title{
Comparison of Energy Absorption in Circular Aluminium Crash Boxes with Rigid and Elastic Boundary Conditions: Numerical and Experimental Investigations
}

\author{
A. Keshavarzi ${ }^{1}$, J. Marzbanrad ${ }^{2}$ and F. Haji Aboutalebi ${ }^{3 *}$ \\ ${ }^{1}$ Department of Mechanical Engineering, Khomeinishahr Branch, Islamic Azad \\ University, Isfahan, Iran \\ ${ }^{2}$ School of Automotive Engineering, Iran University of Science and Technology, \\ Tehran, Iran \\ ${ }^{3}$ Department of Mechanical Engineering, University of Isfahan, 81746-73441, Isfahan, \\ Iran \\ *Email: f.hajiaboutalebi@eng.ui.ac.ir \\ Phone: +983137934110; Fax: +983137932746
}

\begin{abstract}
Crash boxes are usually used in the transportation and automobile industries. Important parameters such as material, boundary conditions, geometry, impact energy consists of striker mass and velocity, and plastic deformation history can influence on the maximum energy absorption and impact load of these structures. In this research first, crash behaviour of extruded aluminium circular tubes under axial impact loading with rigid and elastic boundary conditions are studied. Then, effect of the elastic support on the tube energy absorption is numerically and experimentally investigated. In the following, the numerical results are compared with the practical observations and validated. Finally, it is revealed that employing the elastic support leads to changing deformation mode and significantly reduces the maximum impact load.
\end{abstract}

Keywords: Energy absorption; axial impact loading; elastic boundary conditions; circular aluminium crash boxes; ductile damage criterion.

\section{INTRODUCTION}

The crash boxes are extensively applied in automobile structure to aid the energy absorption. These components have a principle role in absorbing a great deal of impact kinetic energy of crash during the plastic deformation and must be able to save automobile passengers from hazardous injuries or death. Throughout the plastic deformation process, the crash boxes need to be deformed as a sequential folding and collapse mechanisms. To improve the energy absorption and decrease maximum crash load, the process of plastic deformation has to be controlled. During a crash, the energy absorption, maximum crash force, and average crash force are the major parameters to evaluate automobile safety. These parameters depend on many variables such as geometry, material, material porosity, boundary conditions, temperature, plastic deformation history, and impact energy including the striker velocity and mass. In the transportation systems, lower fuel consumption and eventually less carbon dioxide emissions justify lighter and more efficient energy absorber parts. In automotive factories, these limitations force designers to try various methods. One of the most essential methods is to apply the lightweight structures like advanced high-strength steels (AHSS) [1-3], aluminium or magnesium alloys, honeycomb structures [4-7], and 
composite materials [8, 9]. In comparison with conventional steels, these materials generally have low ductility at fracture; strongly endure damage and failure when are subjected to crash loading conditions. Throughout the metalworking, crash box component suffers a plastic deformation history which impresses the crashworthiness response. After the rolling process, sheet metals will be employed in the tension, bending, and stretching dies with varying loading paths and strain rates [10, 11]. Hence, the plastic deformation history affects the crash box dynamic response, an issue considered by many scholars.

Numerous researches have been reported about modelling the behaviour of the crash box and its performance in energy absorption under the frontal crash. To clarify the buckling initiation, Karagiozova and Jones studied the axisymmetric buckling of circular cylindrical shells [12]. The effects of material properties and impact velocity in the critical buckling length which lead to a transition between global and progressive buckling of aluminium alloy circular tubes were experimentally and theoretically examined by Karagiozova and Alves [13,14]. Meanwhile, Hsu and Jones described dynamic axial crushing of aluminium alloy 6063-T6 circular tubes [15]. The inertia influence on the response of structural elements, subjected to explosive loads was taken into account by Karagiozova et al. [16]. Engaging the elastic-plastic material with linear strain hardening, they clearly exhibited the Bauschinger effect.

Galib and Limam analyzed the role of damage on the prediction of the collapsed mode and the energy absorption of aluminium 6060 tubes [17]. Their investigation was founded on the classical Lemaitre-Chaboche uncoupled elastic and plastic damage model. The triggering effect on the energy absorption and crash deformation mode of circular aluminium tubes was obviously presented by Marzbanrad et al. [18]. Also, Jin, Altenhof, and Li carried out a parametric study on the axial cutting, energy absorption, wall thickness, and the number of blades of aluminium 6061-T6 circular crash boxes [19-21]. In the above-mentioned researches, the scholars utilized a simple fracture model established on the maximum strain criterion (i.e. for all stress states, the true fracture strain was supposed to be constant). These simplified models often cause improper predictions of fracture.

Furthermore, Ramalingam and Lankarani [22], and Naghipour et al. [23] primarily suggested the crash with soft soil or water under distributed loading in aerospace industry. In the most presented articles, the crash box structure is assumed to be a rigid support in one side; while, this support is not really rigid, due to flexibility of attached components such as s-rail and firewall. Marzbanrad and Keshavarzi practically and numerically focused on the crash behaviour of square tubes, using an elastic boundary condition instead of rigid type at the bottom of a crash box [24]. In another work, applying ductile failure criterion, Marzbanrad et al. illustrated influence of elastic and plastic support on the energy absorption of the extruded aluminium tubes and found that types of boundary conditions play an important role in behaviour of the structure at crashworthiness [25].

Recently, a few of researchers have contributed to the behaviour of the thinwalled structures and increasing their performance in energy absorption under the frontal crash [26-35]. In this paper, the main objectives are:

i. To employ a ductile damage criterion and numerical simulation of axial crushing test on circular aluminium extruded tubes.

ii. To carry out the experimental crash test of the tubes and validate the numerical simulations. 
iii. To inspect the behaviour of circular tubes under axial loading with several values of support stiffness.

iv. To reveal the elastic support effect on the deformed shape mode and behaviour of the tubes.

\section{DUCTILE DAMAGE MODEL}

Due to a number of mechanisms like nucleation and coalescence of voids, necking instability, and shear band formation, a sheet metal component may endure damage and consequently fracture. Therefore, using a damage criterion to accurately predicting the damage initiation and propagation as well as behaviour of plastic deformation is an essential approach.

Founded on macroscopic strains and stresses, Hooputra et al. offered a comprehensive model for failure prediction of a part under loading [36]. In this criterion, various failure mechanisms consist of ductile and shear fracture, and necking instability are used. In the Hooputra's ductile criterion, the equivalent strain is considered to be as a function of stress triaxiality, established on mathematical model of Kolmogorov [37]. For the isotropic materials, three material dependent parameters are assumed, respecting the non-uniform influence of enhancing the equivalent strain because of increasing the stress triaxiality. The Hooputra's ductile damage model for the isotropic materials is represented as follows:

$\varepsilon_{e q}^{* *}(\eta)=a e^{-c \eta}+b e^{c \eta}$

$\eta=\frac{\sigma_{m}}{\sigma_{e q}}$

where, $\eta, \sigma_{m}, \sigma_{e q}$, and $\varepsilon_{e q}^{* *}$ respectively are the stress triaxiality, mean stress, von Mises equivalent stress, and equivalent plastic strain at fracture or fracture strain. Equation (1) points out an overall relation and contains a non-monotonic reduction of the fracture strain together with growing the stress triaxiality. The criterion is satisfied when the following condition is happened:

$D=\int_{0}^{\varepsilon_{e q}^{* *}} \frac{d \varepsilon_{e q}}{\varepsilon_{e q}^{* *}(\eta)}=1$

in which, $D$ denotes variable of damage and varies from 0 (undamaged material) to 1 (fully fractured material), at each increment monotonically increases with the equivalent plastic strain according to the next equation:

$\Delta D=\frac{\Delta \varepsilon_{e q}}{\varepsilon_{e q}^{* *}(\eta)} \geq 0$

Moreover, $a, b$, and $c$ are the material dependent parameters, empirically determined from three point bending test, Erichsen's cupping test, and waisted tensile specimen and rely on the material, temperature, and strain rate [38]. 


\section{NUMERICAL SIMULATIONS}

Numerical simulations were performed by an explicit finite element method (FEM) code. In the numerical simulations of damage analysis, according to Lemaitre [39], mesh size is recommended to be $0.5-1 \mathrm{~mm}$ for ductile metals. Therefore, four node shell elements with the size of $1 \mathrm{~mm}$ (based on experience and laboratory results) and reduced integration points were used to discretize the circular tubes with dimensions of $\mathrm{L}=300 \mathrm{~mm}, \mathrm{r}=50 \mathrm{~mm}$, and the wall-thickness, $\mathrm{t}=2 \mathrm{~mm}$. The material was stain-rate sensitive aluminium alloy (EN AW-7108 T6). Figure 1 displays the yield stress-plastic strain diagram of the material at various strain rates, created by the relations of [36].

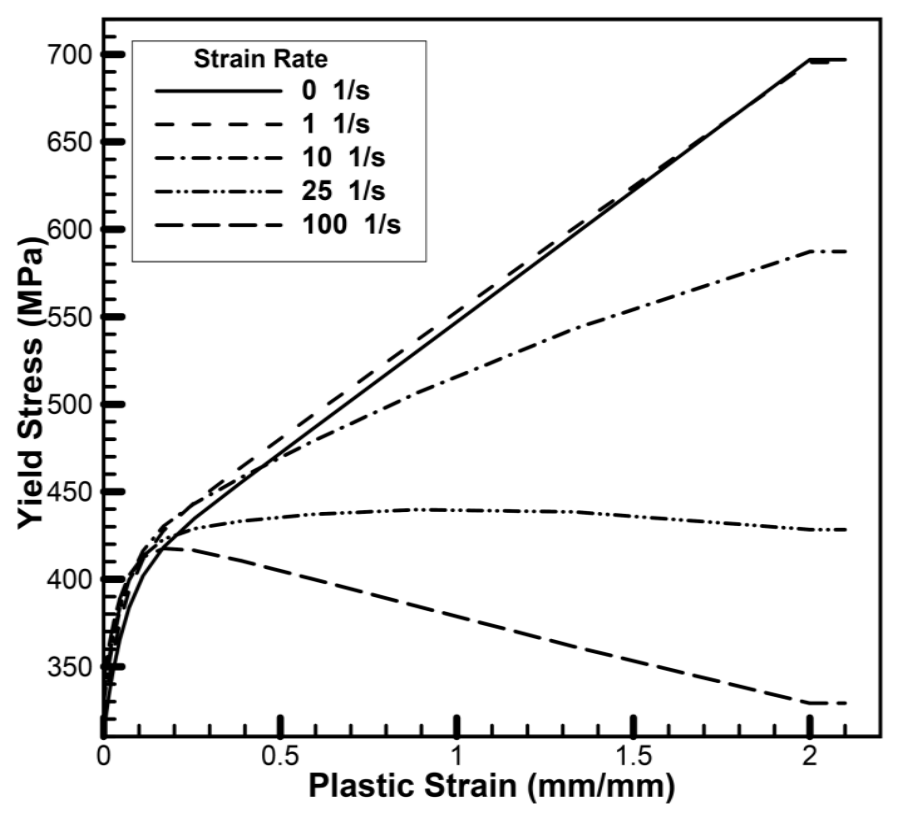

Figure 1. Yield stress-plastic strain diagram of EN AW-7108 T6 [36].

The striker was defined as a point mass, connected to a $125 \mathrm{~kg}$ rigid plate with the initial axial velocity of $10 \mathrm{~m} / \mathrm{s}$. To simulate the rigid support or boundary conditions, tube end was fixed to a rigid surface. Additionally, surface to surface and self-contact interaction with 0.2 friction coefficient was correspondingly assigned to the whole tube surface and contact between the striker and the tube.

In this investigation, for the better analysis of the boundary conditions, two models of tube with rigid and elastic support which is more reality in the practical problems were employed. Figure 2 exhibits a schematic image of the rigid and elastic supports. To simulate the elastic boundary conditions, a diaphragm spring element as the experimental setup was applied at the back of the bottom surface. Because of different ratios of free cone height to thickness, the spring characteristic extensively varied. Empirical tests showed that maximum deflection of the spring with impact velocity of $7.5 \mathrm{~m} / \mathrm{s}$ was $3.92 \mathrm{~mm}$. Hence, the spring stiffness was assumed to be $34194 \mathrm{kN} / \mathrm{m}$ by linearization of the load-deflection nonlinear relation in range of 0 to $4 \mathrm{~mm}$ and this magnitude was assigned in the numerical simulations. The details of determining the spring stiffness were published earlier by the current authors [24].

According to Figure 3, to accurately defining the stiffness of rigid wall, all degrees of freedom of support reference point (RF2) are initially fixed. Then, the 
difference of maximum crash load $d l$ and energy absorption de is taken into account, respecting the next equations:

$$
\begin{aligned}
& d l=\left|100 *\left(M_{L=\infty}^{N}-M_{L=\text { real }}^{E}\right) / M_{k=\infty}^{N}\right| \\
& d e=\left|100 *\left(E_{k=\infty}^{N}-E_{k=\text { real }}^{E}\right) / E_{k=\infty}^{N}\right|
\end{aligned}
$$

in which, $M_{L=\infty}^{N}, M_{L=\text { real }}^{E}, E_{k=\infty}^{N}$, and $E_{k=\text { real }}^{E}$ respectively are maximum crash load with fixed RF2, real maximum crash box with rigid support, energy absorption with fixed RF2, and real energy absorption of crash box with rigid boundary condition. Comparison of the practical and numerical results implied that the most proper value for rigid wall stiffness was $1000 \mathrm{MN} / \mathrm{m}$ which was applied in the numerical simulations. More details of this procedure exist in the previous study of the present authors [24].

(a)

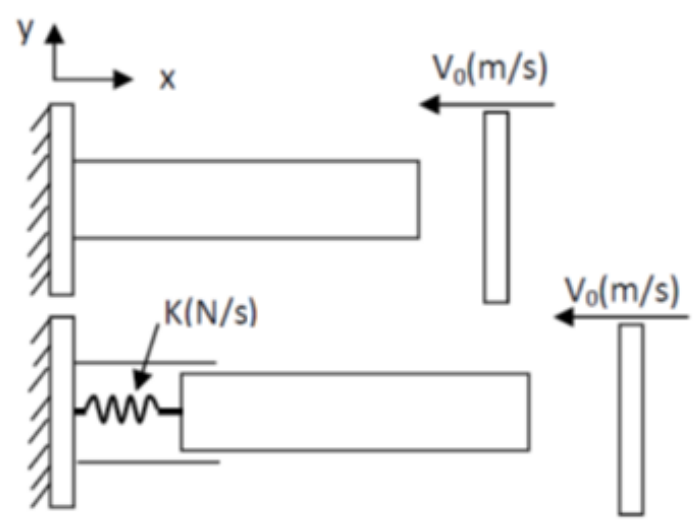

Figure 2. A schematic image of a (a) rigid support and; (b) elastic support.

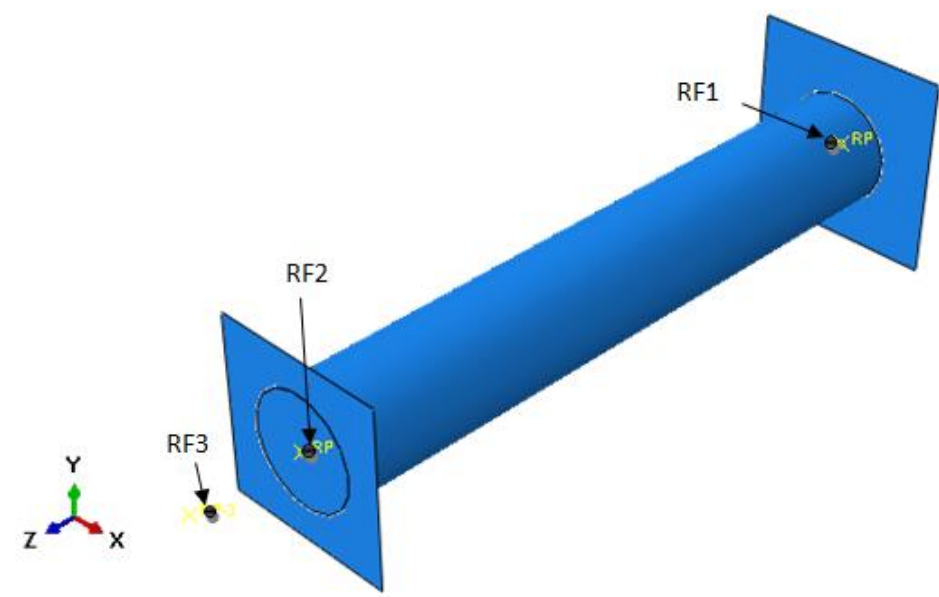

Figure 3. Assembly model of numerical simulations of crash box test.

After the numerical simulations of the crash tests, magnitudes of displacement, velocity, acceleration, and load were extracted. Meanwhile, the tube energy absorption $E_{a b}$, the maximum crash force $P_{\max }$, the mean crash force $P_{\text {mean }}$, and the crash force efficiency 
CFE parameters were estimated by the following approach. $E_{a b}$ represents the tube external work and can be achieved via the next relation:

$$
E_{a b}=\int P(\delta) d \delta
$$

in which, $\delta$ is displacement of the tube and $P(\delta)$ is a function of the crash force. The first peak indicates peak of the crash force, $P_{\max }$ and the area under the crash loaddisplacement chart denotes the absorbed energy. Also, the mean crushing load is defined as the absorbed impact energy per unit of axial deformation [40]:

$$
P_{m}=\frac{1}{\delta} \int_{0}^{\delta} P(\delta) d \delta
$$

The integral sign depicts the area under the load-displacement diagram, is equivalent of the absorbed energy and $d \delta$ represents the total displacement. In other phrase, $P_{m}$ takes into account the absorbed energy per unit of length. To determine the ability of energy absorbing, the crash force efficiency $C F E$, is an essential parameter [41]:

CFE $=\frac{P_{m}}{P_{\max }} * 100$

To illustrate the characteristics of absorber, $P_{m}$ and $P_{\max }$ are the two important and effective parameters. More value of the absorbed energy is a favorite characteristic for the crash box and is obtained with the larger magnitude of $P_{m}$. It means that all efforts are carried out to reduce the peak force magnitude $P_{\max }$. In the energy absorbers design, $C F E$ is a very major parameter; greater values indicate more energy absorption of the absorber with less peak force and is the best benchmark for comparing the results.

\section{EXPERIMENTAL TEST}

The empirical tests were done by a dynamic test rig arrangement. The test rig had a mass of 140 to $500 \mathrm{~kg}$ which could slip on $10 \mathrm{~m}$ rail, produced $13 \mathrm{~m} / \mathrm{s}$ maximum impact speed with a striker mass of $150 \mathrm{~kg}$. Additionally, the experimental test rig was equipped by:

i. Data acquisition system for recording the displacement, acceleration, and load.

ii. Measurement system architecture to control the measurement system and reveal the measurement data vs. time.

iii. Software management to remove the quantization and process noises in the measurement.

More details of the experimental setup can be found in [24].

\section{NUMERICAL AND EXPERIMENTAL RESULTS}

In this research, four kinds of aluminium circular tubes with respective length, diameter, and thickness of $300 \mathrm{~mm}, 50 \mathrm{~mm}$ and $2 \mathrm{~mm}$ were prepared and tested. A0, A1, A2, and A3 specimens are tubes correspondingly impact to a rigid wall support, a very hard 
elastic boundary condition $(\mathrm{k}=10 \mathrm{GN} / \mathrm{ma})$, a hard-elastic support $(\mathrm{k}=1 \mathrm{GN} / \mathrm{ma})$, and a soft boundary condition $(\mathrm{k}=0.1 \mathrm{GN} / \mathrm{ma})$. Figures 4 and 5 show the numerical and experimental results, and comparison between them.

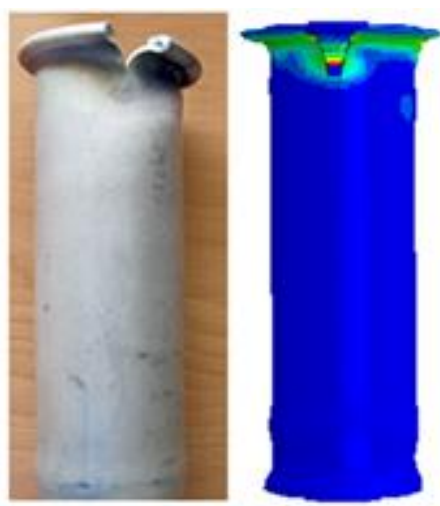

(a) A0

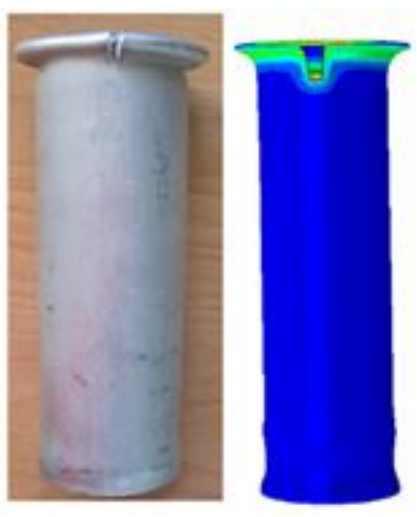

(b) A1

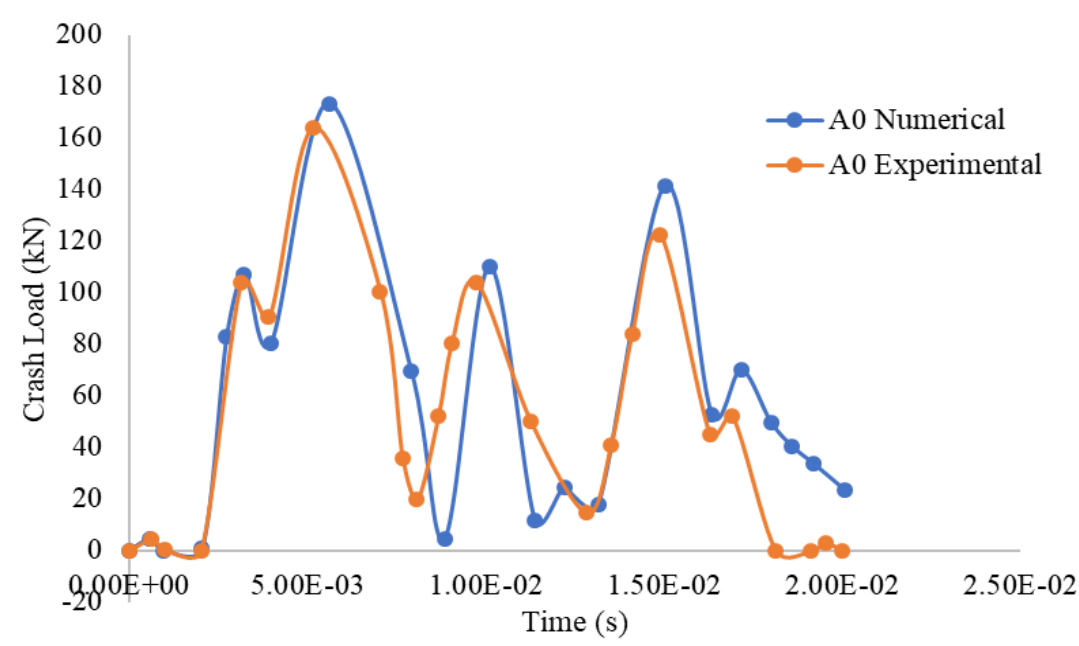

(c)

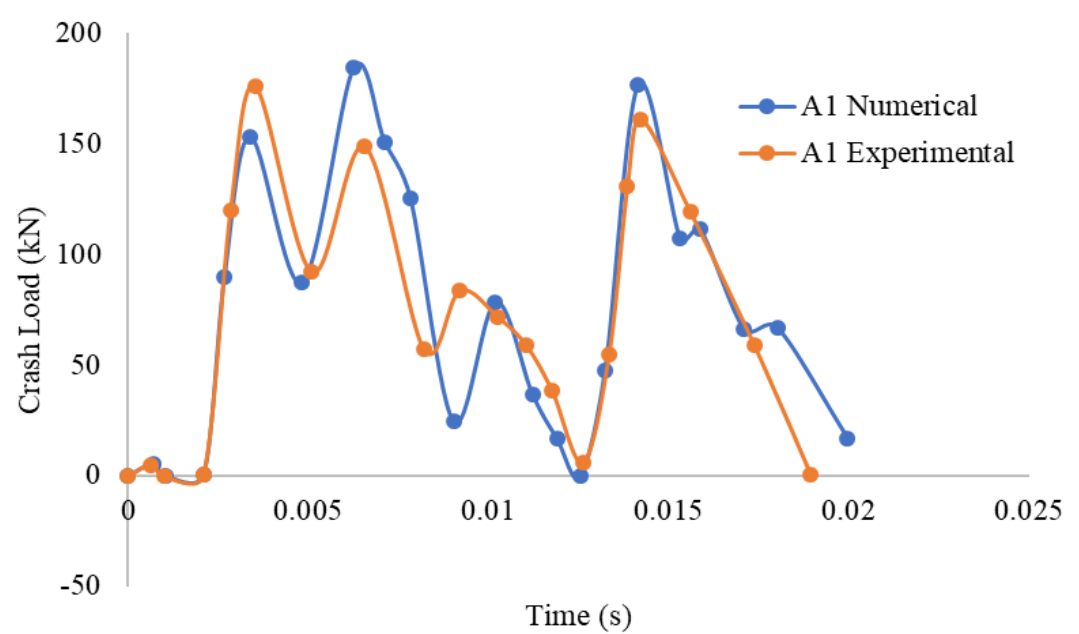

(d) 


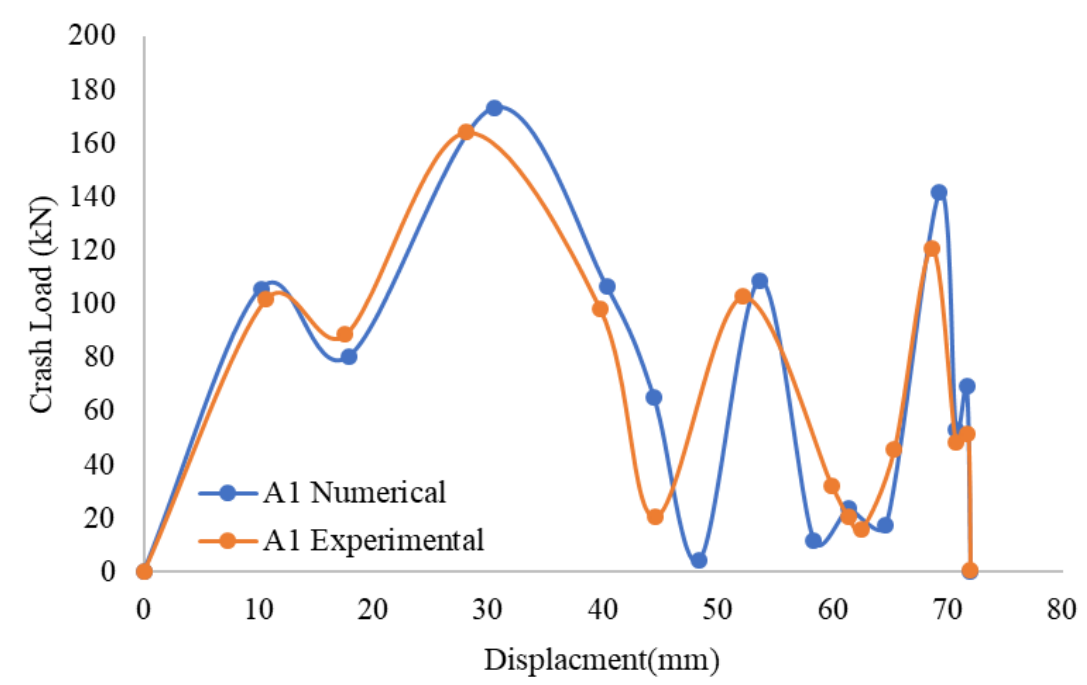

(e)

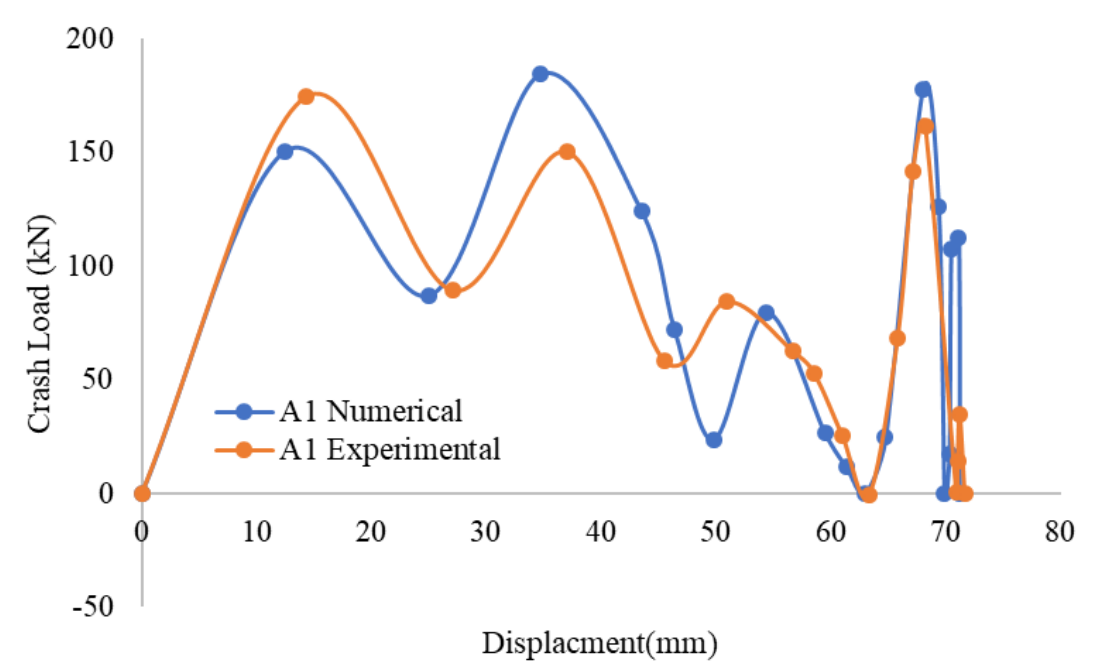

(f)

Figure 4. Experimental and numerical results of specimen (a) A0 (rigid support) and; (b) A1 (k=10GN/ma) for (c), (d) crash load-time and; (e), (f) crash load-displacement.

In Figure 4 and 5, image (a) and (b) display the numerical and empirical results of the crash tests. Graph (c) and (d) represent the crash load-time diagram, and the graphs in (e) and (f) depict the crash load-displacement throughout the crash test. The figures signify that in the cases of the solid and very hard elastic support, a fracture mode is happened in the tube front; while, the tube is axially compressed and plastically deformed without any fracture in the other cases. Although, the numerical values of crash load are a little different from the empirical magnitudes but as the figures approve, the numerical simulations are able to correctly follow the deformation mode, ultimate displacement or the maximum axial deformation, the maximum and the mean crash load. Meanwhile, it is realized that there is a maximum alteration between the numerical and practical results of maximum crash load. This difference seems to be because of the friction effect of the sled and the rail which causes the energy absorption or probably errors in the measurement instruments. 


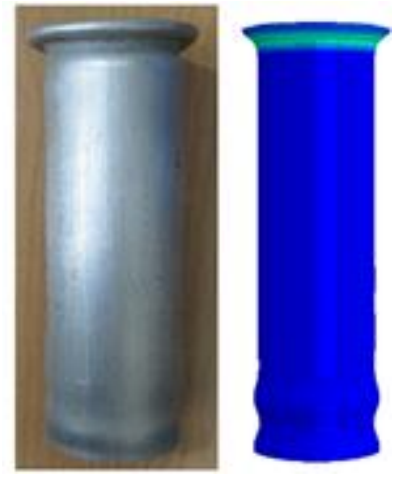

(a) $\mathrm{A} 2$

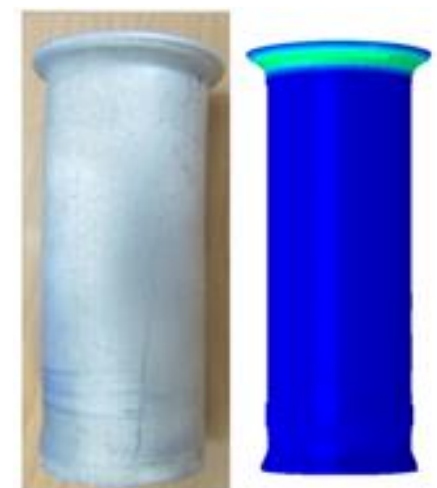

(b) $\mathrm{A} 3$

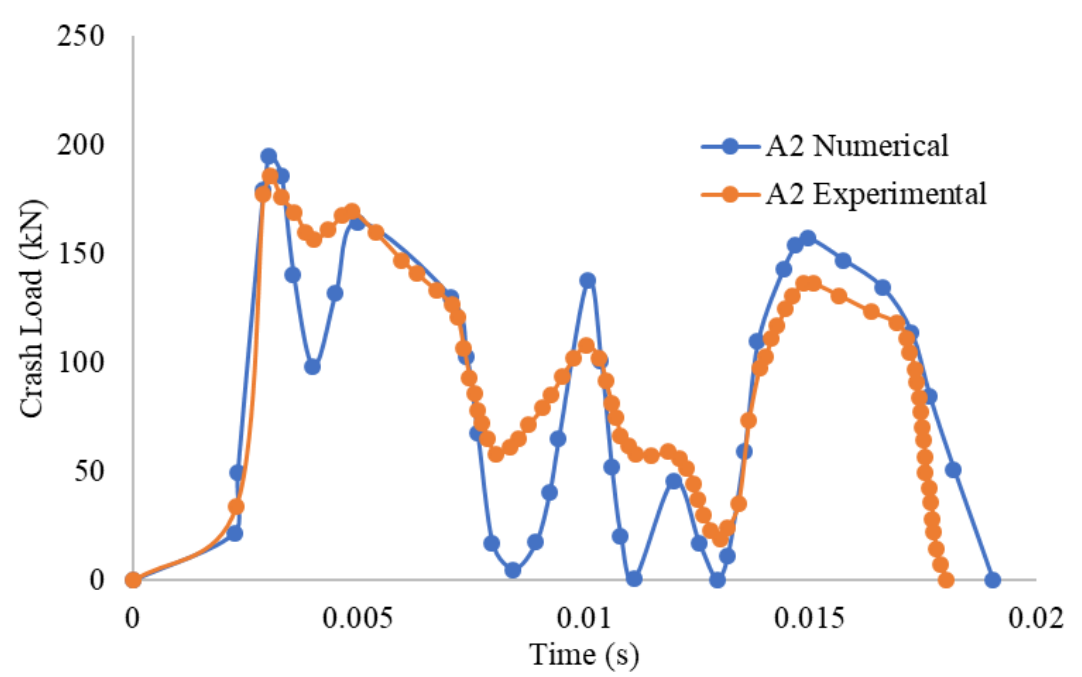

(c)

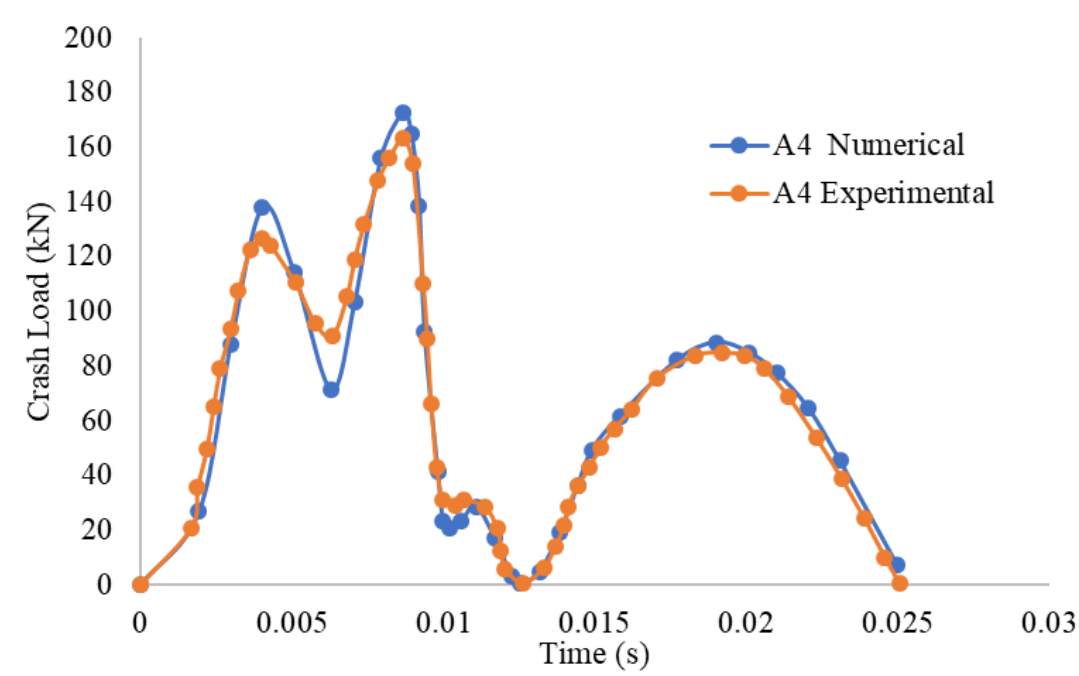

(d) 


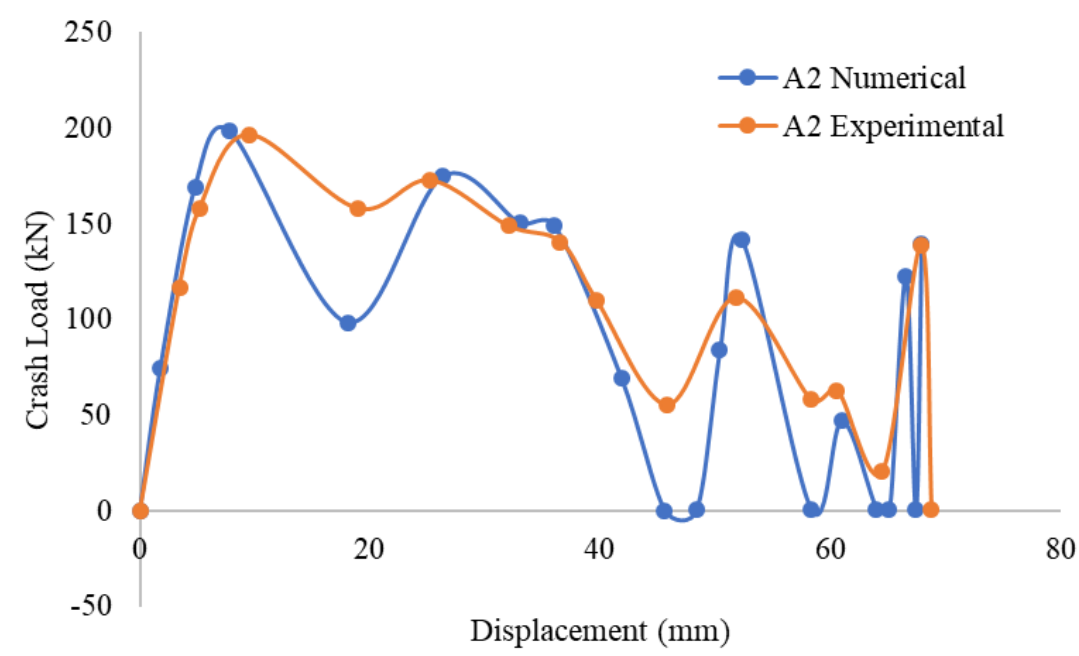

(e)

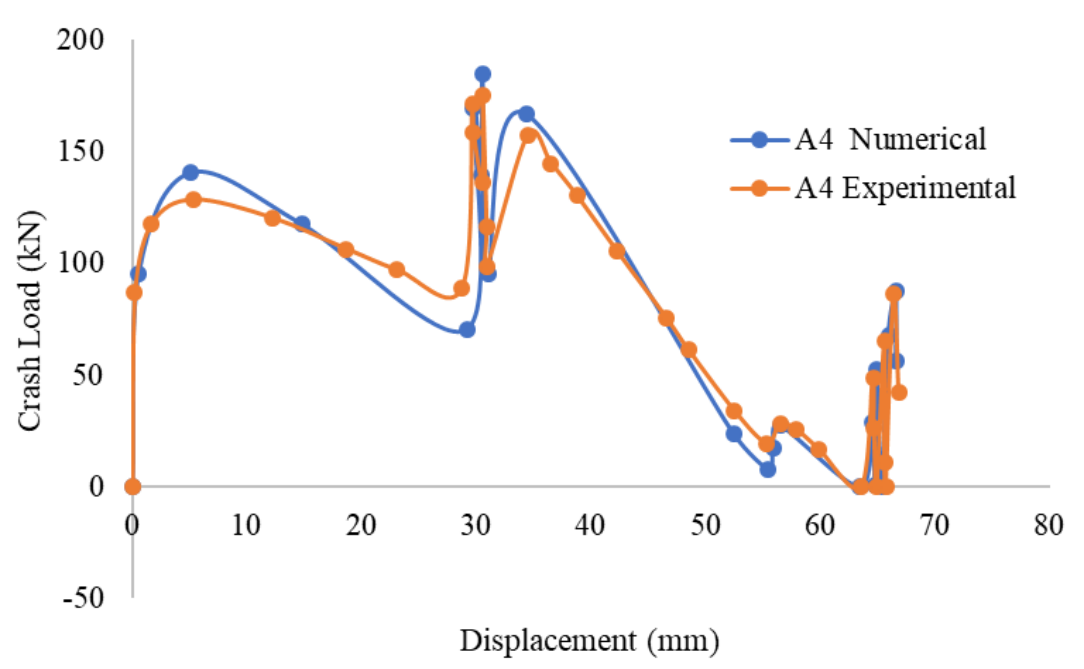

(f)

Figure 5. Experimental and numerical results of specimen (a) A2 (k=1GN/ma) and; (b) A3 $(\mathrm{k}=0.1 \mathrm{GN} / \mathrm{ma})$ for $(\mathrm{c})$, (d) crash load-time and; (e), (f) crash load-displacement.

The two modes of deformation and fracture, and the concertina mode can be seen in the samples $\mathrm{A} 0$ and $\mathrm{A} 1$, while, in the $\mathrm{A} 2$ and $\mathrm{A} 3$ specimens only concertina mode can be observed, since the maximum crash load reduces in the A2 and A3 and the fracture mode is not created. Comparison between the numerical and experimental data of crash test include of the maximum crash load, the energy absorption, ultimate displacement or the maximum axial deformation, and $C F E$ for all the specimens are presented in Table 1 and the percent of errors are demonstrated in Table 2. Table 1 and 2 clarify that the numerical results are in good agreement with the practical tests and there are no major variances between them. The peak crash force in the rigid support sample (A0) is less than the elastic support cases (A1, A2, and A3), while the maximum axial deformation $\Delta$ for $\mathrm{A} 0$ is greater than the A1, A2, and A3 specimens. Besides, the energy absorption of samples with the elastic conditions is smaller than the rigid support type. This is due to this fact that the elastic supports have lower deformation when 
compared with the rigid conditions. Finally, it can be concluded that the CFE magnitude of the rigid support is upper than the elastic boundary condition samples.

Furthermore, the results show that adding the elastic support, the difference between the numerical and experimental results is usually higher. For example, in sample A3, this difference in the amount of energy absorbed and the CFE is greater than the specimen A0. This can be because by softening the spring stiffness in the laboratory model, it becomes nonlinear, while, the spring is considered to be linear in the numerical simulations.

Table 1. Comparison between the numerical and experimental data of crash test.

\begin{tabular}{lcccccccc}
\hline $\begin{array}{l}\text { Test } \\
\text { No. }\end{array}$ & $P_{\max }^{N}(k N)$ & $P_{\max }^{E}(k N)$ & $E_{\text {in }}^{E}(k J)$ & $E_{\text {in }}^{N}(k J)$ & $\Delta^{E}(m m)$ & $\Delta^{N}(m m)$ & $C F E^{E}(\%)$ & $C^{2} F E^{N}(\%)$ \\
\hline A0 & 165 & 160 & 5.81 & 6.13 & 0.72 & 0.71 & 92.96 & 98.08 \\
A1 & 168 & 168 & 5.16 & 6.05 & 0.73 & 0.72 & 82.56 & 96.80 \\
A2 & 188 & 198 & 4.36 & 5.91 & 0.70 & 0.69 & 69.76 & 94.56 \\
A3 & 185 & 173 & 4.05 & 5.73 & 0.65 & 0.64 & 64.80 & 91.68 \\
\hline
\end{tabular}

Table 2. The error of numerical results compares to the experimental data.

\begin{tabular}{lcccc}
\hline Test No. & $\begin{array}{c}\text { Error of max. } \\
\text { crash load }(\%)\end{array}$ & $\begin{array}{c}\text { Error of energy } \\
\text { absorption }(\%)\end{array}$ & $\begin{array}{c}\text { Error of max. axial } \\
\text { deformation }(\%)\end{array}$ & $\begin{array}{c}\text { Error of CFE } \\
(\%)\end{array}$ \\
\hline A0 & 3.0 & 5.20 & 1.3 & 5.20 \\
A1 & 5.6 & 14.7 & 1.3 & 14.7 \\
A2 & 6.0 & 26.2 & 1.4 & 26.2 \\
A3 & 6.5 & 29.3 & 1.5 & 29.3 \\
\hline
\end{tabular}

\section{CONCLUSION}

In this paper, a ductile failure criterion and a number of circular tubes that was subjected to axial loading with rigid and elastic boundary conditions were numerically simulated. Experimental tests were carried out according to the numerical analyses and compared with the numerical results. Comparison of the numerical and practical results showed a good adaptation which verified the numerical simulations. Furthermore, the results revealed that the maximum axial deformation and the energy absorption could be altered by elastic support stiffness. Meanwhile, it was confirmed that during the crash, in comparison with the elastic support, the circular crash box with the rigid boundary condition was able to absorb more energy. Moreover, the energy absorption could be increased by growing the spring stiffness. The current research proved that elastic components, attached to the crash box like firewall and S-rail impressed the crash box behaviour. Hence, it is concluded that in the structural design of vehicles, the automotive engineers must pay attention to the support structure stiffness of crash box and the structure stiffness behind the crash box must be seriously noticed. Also, nonlinearity of the spring behaviour causes the differences between numerical and experimental results. In order to reduce the error in such matters, it is suggested that a nonlinear spring model is utilised. 


\section{REFERENCES}

[1] Dai HL, Yan X, Jiang HJ. Investigation on thermomechanical behaviour of a HSLA steel circular plate under impact load. International Journal of Mechanics and Materials in Design 2014; 10(4): 411-420.

[2] Safari H, Nahvi H, Esfahanian M. Improving automotive crashworthiness using advanced high strength steels. International Journal of Crashworthiness 2017; 5: $1-15$.

[3] Xu F, Sun G, Li G, Li Q. Experimental study on crashworthiness of tailorwelded blank (TWB) thin-walled high-strength steel (HSS) tubular structures. Thin-Walled Structures 2014; 74: 12-27.

[4] Yin H, Wen G. Theoretical prediction and numerical simulation of honeycomb structures with various cell specifications under axial loading. International Journal of Mechanics and Materials in Design 2011; 7(4): 253-263.

[5] Mohammadiha O, Beheshti H, Haji Aboutalebi, F. Multi-objective optimisation of functionally graded honeycomb filled crash boxes under oblique impact loading. International journal of crashworthiness 2014; 20: 4-59.

[6] Archut JL, Vinyas, Upadhyaya YS. Estimation of Damage Value of SAE4340 Steel and 5A02 Aluminium Alloy. International Journal of Automotive and Mechanical Engineering 2018; 15(2): 5211-5220.

[7] Demirci E, Yildiz AR. An investigation of the crash performance of magnesium, aluminium and advanced high strength steels and different cross-sections for vehicle thin-walled energy absorbers. Materials Testing 2018; 60(7-8): 661-668.

[8] Lu G, Yu T. Energy absorption of materials and structures, Woodhead Publishing, Cambridge; 2003; 268-373.

[9] Zhan B, Sun L, Huang B. Progressive failure prediction of FRP tubes by modified damage model. International Journal of Crashworthiness 2017; 5: 1-12.

[10] Papadakis L, Schober M, Zaeh MF. Numerical investigation of the influence of preliminary manufacturing processes on the crash behaviour of automotive body assemblies. International Journal of Advanced Manufacturing Technology 2013; 65(5-8): 867-880.

[11] Zhu P, Lu J, Ji Q, Cheng Z. Experimental study of in-plane mechanical performance of carbon/glass hybrid woven composite at different strain rates., International Journal of Crashworthiness 2016; 21(6): 542-554.

[12] Karagiozova D, Jones N. Dynamic elastic-plastic buckling of circular cylindrical shells under axial impact. International Journal of Solids and Structures 2000; 37(14): 2005-2034.

[13] Karagiozova D, Alves ML. Transition from progressive buckling to global bending of circular shells under axial impact-Part I: Experimental and numerical observations. International Journal of Solids and Structures 2004; 41(5-6): 1565-1580.

[14] Karagiozova D, Alves ML. Transition from progressive buckling to global bending of circular shells under axial impact-Part II: Theoretical analysis. International journal of solids and structures 2004; 41(5-6): 1581-1604.

[15] Hsu S, Jones N. Dynamic axial crushing of aluminium alloy 6063-T6 circular tubes. Latin American Journal of Solids and Structures 2004; 1(3): 277-296.

[16] Karagiozova D, Nurick G, Yuen SCK. Energy absorption of aluminium alloy circular and square tubes under an axial explosive load. Thin-walled structures 2005; 43(6): 956-982. 
[17] Al Galib D, Limam A. Experimental and numerical investigation of static and dynamic axial crushing of circular aluminium tubes. Thin-Walled Structures 2004; 42(8): 1103-1137.

[18] Marzbanrad J, Abdollahpoor A, Mashadi B. Effect of the triggering of circular aluminium tubes on crashworthiness. International Journal of Crashworthiness 2009; 14: 591-599.

[19] Jin SY, Altenhof W. An experimental study investigating the influence of the number of blades in a cutter used in axial cutting of AA6061-T6 and T4 round tubes. SAE International Journal of Materials and Manufacturing 2010; 3(1): 174-185.

[20] Jin SY, Altenhof W. An analytical model on the steady-state deformation of circular tubes under an axial cutting deformation mode. International Journal of Solids and Structures 2011; 4: 269-279.

[21] Jin SY, Altenhof W, Li Z. A parametric study on extrusion geometry and blade quantity during axial cutting deformation of circular AA6061-T6 extrusions under impact and quasi-static loading. International Journal of Impact Engineering 2012; 49: 165-178.

[22] Ramalingam VK, Lankarani HM. Analysis of impact on soft soil and its application to aircraft crashworthiness. International journal of crashworthiness 2002, 7(1): 57-66.

[23] Naghipour P, Aktay L, Johnson AF. Numerical investigation of structural crash response of thin-walled structures on soft soil. Materials and Design 2008; 29(10): 2052-2060.

[24] Marzbanrad J, Keshavarzi A. A Numerical and experimental study on the crash behaviour of the extruded aluminium crash box with elastic support. Latin American Journal of Solids and Structures 2014; 11(8): 1329-1348.

[25] Marzbanrad J, Keshavarzi A, Haji Aboutalebi F. Influence of elastic and plastic support on the energy absorption of the extruded aluminium tube using ductile failure criterion. International Journal of Crashworthiness 2014; 19(2): 172-181.

[26] Zhou C, Wang B, Ma J, You Z. Dynamic axial crushing of origami crash boxes. International journal of mechanical sciences 2016; 118: 1-12.

[27] Zhou C, Zhou Y, Wang B. Crashworthiness design for trapezoid origami crash boxes. Thin-Walled Structures 2017; 117: 257-267.

[28] Ince ST, Kumar A, Park D, Paik JK. An advanced technology for structural crashworthiness analysis of a ship colliding with an ice-ridge: Numerical modelling and experiments. International journal of impact engineering 2017; 110: 112-122.

[29] Kohar CP, Brahme A, Imbert J, Mishra RK, Inaal K. Effects of coupling anisotropic yield functions with the optimization process of extruded aluminium front rail geometries in crashworthiness. International Journal of Solids and Structures 2017; 128: 174-198.

[30] Yang X, Ma J, Shi Y, Sun Y, Yang J. Crashworthiness investigation of the bioinspired bi-directionally corrugated core sandwich panel under quasi-static crushing load. Materials and Design 2017; 135: 275-290.

[31] Zhang L, Bai Z, Bai F. Crashworthiness design for bio-inspired multi-cell tubes with quadrilateral hexagonal and octagonal sections. Thin-Walled Structures 2018; 122: 42-51. 
[32] Pety SJ, Gendusa AC, Barnett PR, Calvert QA, Sottos NR. Effect of microchannels on the crashworthiness of fiber-reinforced composites. Composite Structures 2018; 184: 428-436.

[33] Zahran M, Xue P, Esa MS, Abdelwahab MM. A novel tailor-made technique for enhancing the crashworthiness by multi-stage tubular square tubes. Thin-Walled Structures 2018; 122: 64-82.

[34] Zhang Y, Xu X, Sun G, Lai X, Li Q. Nondeterministic optimization of tapered sandwich column for crashworthiness. Thin-Walled Structures 2018; 122: 193207.

[35] Chen S, Yu H, Fang, J. A novel multi-cell tubal structure with circular corners for crashworthiness. Thin-Walled Structures 2018; 122: 329-343.

[36] Hooputra H, Gese H, Dell H, Werner H. A comprehensive failure model for crashworthiness simulation of aluminium extrusions. International Journal of Crashworthiness 2004; 9: 449-464.

[37] Kolmogorov W. Spannungen Deformationen Bruch. Metallurgija 1970; 230235.

[38] Hill MR, Panontin TL. Micromechanical modelling of fracture initiation in 7050 aluminium, Engineering Fracture Mechanics 2009; 69: 2163-2186.

[39] Lemaitre J. A course on damage mechanics, Berlin, Springer; 1996.

[40] Acar E, Guler MA, Gerceker B. Multi-objective crashworthiness optimization of tapered thin-walled tubes with axisymmetric indentations. Thin-Walled Structures 2011; 49: 94-105.

[41] Alavinia A, Fallah Nejad KH, Badnava H, Farhoudi HR. Effects of buckling initiators on mechanical behaviour of thin-walled. Thin-Walled Structures 2012; 59: 87-96. 